\title{
Evaluation of histopathological and ultrastructural changes in the testis of tadalafil treated adult male albino rats
}

Hagar A. Hashish

Correspondence: nada_2612@yahoo.com

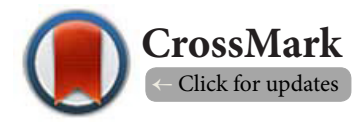

Department of Anatomy and Embryology, Faculty of Medecine, Mansoura University, Egypt.

\begin{abstract}
Background: Male infertility is a private problem. There was no ideal medication for treatment of the infertile males. PDE5 inhibitors are line of management for male infertility. Tadalafil is efficient and selective PDE5 Inhibitor. It is known to cause less visual manifistations in contrast to the other drugs.

Aim of the work: This study was designed to evaluate the effect of tadalafil on the histologicsl structure and ultrastructure of adult male albino rats testis.

Material and methods: Twenty-four adult male albino rats were divided into 4groups; control and 3treated groups (T1,T2,T3). Tadalafil was given orally to the treated groups in 3 different doses for 30 days. At the end of the experiment, test is was dissected for histological and electron microscopic study.

Results: Light microscopic examination of T1 revealed normal structure of tubules with intercellular vacuoles. T2 showed thin irregular thin basement membrane, more vacuoles and congested blood vessels. T3 showed acidophilic exudate in the lumen of the tubules with degenerated germinal cells. The electron microscopic examination of T1 showed normal germinal cells structure with some dilated mitochondria. T2 revealed irregular nuclear membrane of both Sertoli and spermatogonia cells. T3 showed interrupted interSertoli junctional specialization, irregular nuclear membrane in sertoli and Leydig cells. Round spermatid showed loss of acrosomal cap.
\end{abstract}

Conclusion: It can be concluded that, long-term daily use of tadalafil can lead to noticeable pathological effect in the testis which may be implicated in male fertility.

Keywords: Tadalafil, testis, sertoli cells, seminefrous tubules, leydig cells

\section{Introduction}

Male infertility is a private problem. However the assisted reproductive technology (ART) is a line of management for infertility due to male etiology, significant percent of infertile males still infertile after intrauterine insemination or in vitro fertilization (IVF) techniques. There was no ideal medication for treatment of the infertile males. So, it appears that modern medication with a positive effect on male infertility is essential. PDE5 (PhosphoDiestrase Enzyme) inhibitors are line of management for male infertility [1].

It is known that inhibition of the enzyme phosphodiesterase (PDE) type 5 can maintain nitric oxide induced smooth muscle relaxation in the corpus cavernosum of penis and socause penile erection [2,3]. PDE5 is well expressed in the smooth muscle cells of the penile corpus cavernosum and the smooth muscle cells in blood vesselsin the lung, so PDE5 inhibitors can manage erectile dysfunction (ED) [4] and pulmonary hypertension [5].

Although the most of the data about PDE5 inhibitors and ED comes from studies on sildenafil [6], two new PDE5 inhibitors; tadalafil [7] and vardenafil [8] are recently available for the treatment of ED.

The three PDE- 5 inhibitors have same mode of action, but their selectivity differs for PDE-5. Sildenafil and vardenafilless selective for PDE5 than tadalafil [9].

Tadalafil is efficient, reversible and selective PDE5 Inhibitor. It is used as an oral therapy in ED casused by psychological, organic or mixed factor [7]. It is a long-acting therapy [10]. Its half-life is about 17.5 hour, high-fat foods do not interfere 
with tadalafil's absorption rate in contrast with Sildenafil and vardenafil [11]. Tadalafil is also known to cause less visual manifistations like abnormal color vision in contrast to the other two drugs [9].

This study was designed to evaluate the effect of tadalafil on the histologicsl structure and ultrastructure ofadult male albino rats testis.

\section{Materials and methods}

\section{Experimental animals}

Twenty-four adult male albino rats (4-6 months old, 200-350gm weight) were used. The use of the animals was prospectively approved by the Committee at Mansoura University, Faculty of Medicine. The rats were housed in the Animal Care Centre of Mansoura faculty of Pharmacy. The rats were provided with fresh food and water daily and inspected for any possible signs of infection (e.g., redness or ulceration of skin).

\section{Experimental design}

Animals were divided into four groups (6 rats each). The first group used as a control group. The other three groups were used as treated groups.

\section{Tadalafil administration}

Group 1 (Control group ): received oral saline solution via orogastric feeding tube for 4 weeks.

Group 2 (treated): $9 \mathrm{mg} / \mathrm{kg}$ tadalafil dissolved in distilled water daily for 30 days, through orogastric feeding tube (equivalent to $10 \mathrm{mg}$ adult human dose).

Group 3 (treated): received $1.8 \mathrm{mg} / \mathrm{kg}$ tadalafil dissolved in distilled water daily for 30 days, through orogastric feeding tube(equivalent to $20 \mathrm{mg}$ adult human dose) [12].

Group 4(treated): received $2.6 \mathrm{mg} / \mathrm{kg}$ body weight of tadalafil dissolved in distilled water daily for 30 days, through orogastric feeding tube. The giving doses were similar to the recommended human oral doses $40 \mathrm{mg}$. Tadalafil was supplied from Pfizer Inc. (Pfizer, Egypt), stored at $2-4^{\circ} \mathrm{C}$ and protected from sunlight.

\section{Histological analysis}

At the end of treatment, rats of each group were anaesthetized with with Ketamine $(60 \mathrm{mg} / \mathrm{kg}$ i.p.) and perfused intracardially with $0.9 \% \mathrm{NaCl}$, followed by $4 \%$ paraformaldehyde in $0.1 \mathrm{M}$ phosphate buffer (PB) pH 7.2. The testis was carefully dissected and removed. Both testiswere taken and weighted. one of them was immersed in $0 \%$ paraformaldehyde solution for 24 hours. The specimens were processed for paraffin sections of $5 \mu \mathrm{m}$ thickness and stained with H\&E for histological examination.

\section{Tissue preparation for ultrastructural study}

The other testis was cut into small pieces $1 \mathrm{~mm}^{3}$ each. Specimens were immediately fixed in cold $3.5 \%$ glutaraldehyde and washed in $0.1 \mathrm{M}$ phosphate buffer (PH 7.2). Then, postfixed with $1 \%$ osmium tetraoxide (OsO4), dehydrated and embedded in epoxy resin. Semithin sections ( $1 \mu \mathrm{m}$ thick) were cut on an LKB ultratome and stained with toluidine blue stain and examined by light microscope. Ultrathin sections (50-70nm thick) were cut, mounted on copper grids, stained with uranyl acetate and lead citrate [13]. Sections were examined by JEOL-100SX transmission electron microscope provided with a digital camerain the Electron Microscopic Unit of Tanta Faculty of Medicine.

\section{Quantitative analysis}

The transverse and longitudinal diameters of the seminiferous tubules were measured. The number of cells in tests were measured in a fixed field in serial sections by LeicaQuin 500" image analyzer computer system (England). The cells were counted in five fixed non-overlapping microscopic fields using a 100 xobjective lens.

\section{Statistical analysis}

Statistical analysis was done using computer software SPSS program (statistical package for social science) version 10. All data were expressed as the mean \pm SD. The significance level considered was $P \leq 0.05$.

\section{Results \\ Light microscopic examination \\ Group 1 (control group)}

Histological examination of H\&E and toluidine blue stained sections in the testis of the control group showed multiple rounded seminiferous tubules with regular outlines. They were lined by 4-6 layers of germinal epithelium at different stages of spermatogenesis. The flagella of mature sperms were seen in the lumen of the tubules. The lining epithelium consisted of Sertoli cells and other germinal cells. Sertoli cells appeared pyramidal in shape and resting on the basement membrane. The germinal epithelium consisted of spermatogonia, 1ry spermatocytes, rounded spermatids and elongated spermatids. The interstitial spaces in-between the tubules contained Leydig cells and some blood vessels (Figure 1).

\section{Group 2 (treated-T1)}

$\mathrm{L} / \mathrm{M}$ examination of testicular sections of this group showed seminiferous tubules with germinal epithelium. The flagella of sperms were obvious in the lumen. Sertoli cells were seen resting on the basement membrane. The spermatogenic cells were noticed; 1 ry spermatocyte, round spermatid and elongated sperms. Areas of intercellular vacuoles were detected. The interstitial space showed some Leydig cells seperated bycongested blood vessels (Figure 2).

\section{Group 3 (treated-T2)}

L/M examination of testicular sections of this group showed some seminiferous tubules with irregular outline. The flagella of sperms were obvious in the lumen. Sertoli cells were seen resting on the thin, irregular basement membrane. The spermatogenic cells were noticed; 1ry spermatocyte, round 


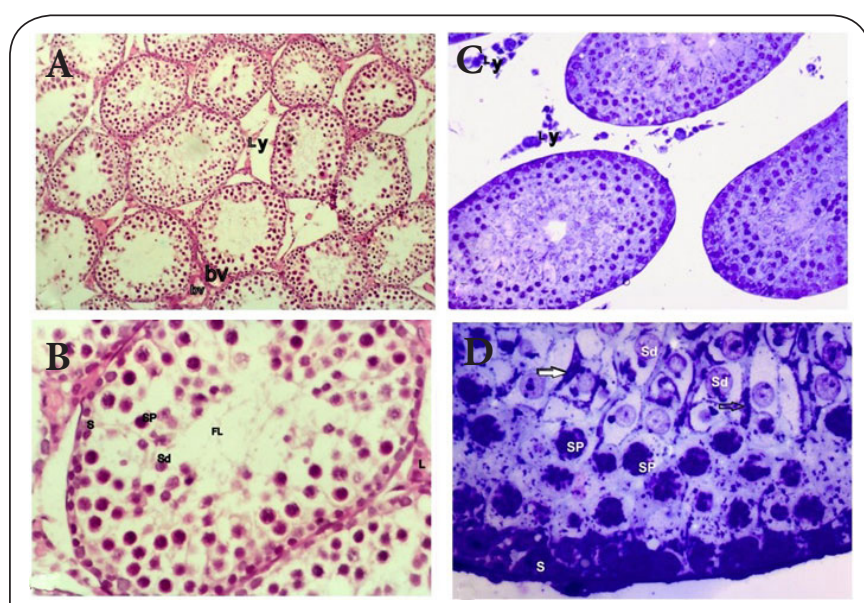

Figure 1. Photomicrograph of sections in control tests; A. Multiple rounded seminiferous tubules with regular outlines, lined by layers of germinal epithelium. The interstitial spaces in-between the tubules contain Leydig cells (Ly) and some blood vessels (bv) (H\&E x100). B. The flagella of mature sperms are seen in the lumen of the tubules (FL), Sertoli cells (S), 1ry spermatocyte (Sp), rounded spermatids (Sd) (H\&E x400). C. Seminefrous tubules with interstial cells of leydig (Ly) (Touldine blue x100). D. Higher magnification of C, showing Sertoli cells (S), 1ry spermatocyte (Sp), rounded spermatids (Sd), elongated spermatid (arrows) (Touldine blue $\mathrm{x} 400$ ).
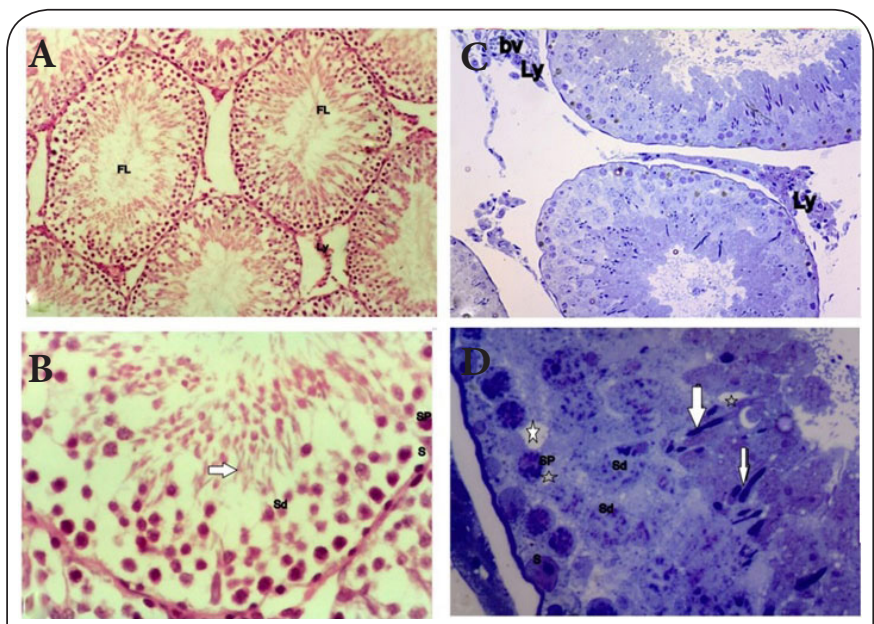

Figure 2. Photomicrograph of sections in treated tests (T1); A. Seminiferous tubules with germinal epithelium. The flagella of mature sperms are seen in the lumen of the tubules (FL). The interstitial spaces in-between the tubules contain Leydig cells (Ly) (H\&E x100). B. Sertoli cells are resting on the basement membrane (S). The spermatogenic cells are noticed; 1ry spermatocyte $(\mathrm{Sp})$, round spermatid $(\mathrm{Sd})$ elongated sperms (arrow) (H\&E x400). C. Seminefrous tubules with interstial cells of leydig (Ly) and congested blood vessels (bv) (Touldine blue x100). D. Higher magnification of $\mathbf{C}$, showing Sertoli cells (S), 1ry spermatocyte (Sp), rounded spermatids (Sd), elongated spermatid (arrows) Areas of intercellular vacuoles are detected $\left({ }^{*}\right)$ (Touldine blue $\left.\mathrm{x} 400\right)$.

spermatid and elongated sperms. More areas of intercellular vacuoles were detected. The interstitial space showed some Leydig cells seperated by congested blood vessels (Figure 3).

\section{Group 4 (treated-T3)}

$\mathrm{L} / \mathrm{M}$ examination of testicular sections of this group showed seminiferous tubules with irregular outline with acidophilic exudate in their lumen. Some spermatogenic cells showed signs of degeneration, vacuolated cytoplasm and pyknotic nuclei. Increased areas of cellular loss and vaculation. Congested blood vessels between tubules (Figure 4).

\section{Transmission electron microscopic results (TEM) Group 1 (control group)}

The ultrastructure of the control testis showed Sertoli cell, were resting on the basement membrane with adjacent myoid cell. The nucleus appeared triangular and euchromatic with welldeveloped nucleolus. The cytoplasm showed some organelles like mitochondria, and ribosomes. The inter-Sertoli junctional specialization with adjacent cells was apparent (Figure 5A). The germinal epithelium showed different stages of maturation. The primary spermatocytes appeared as large rounded cells,

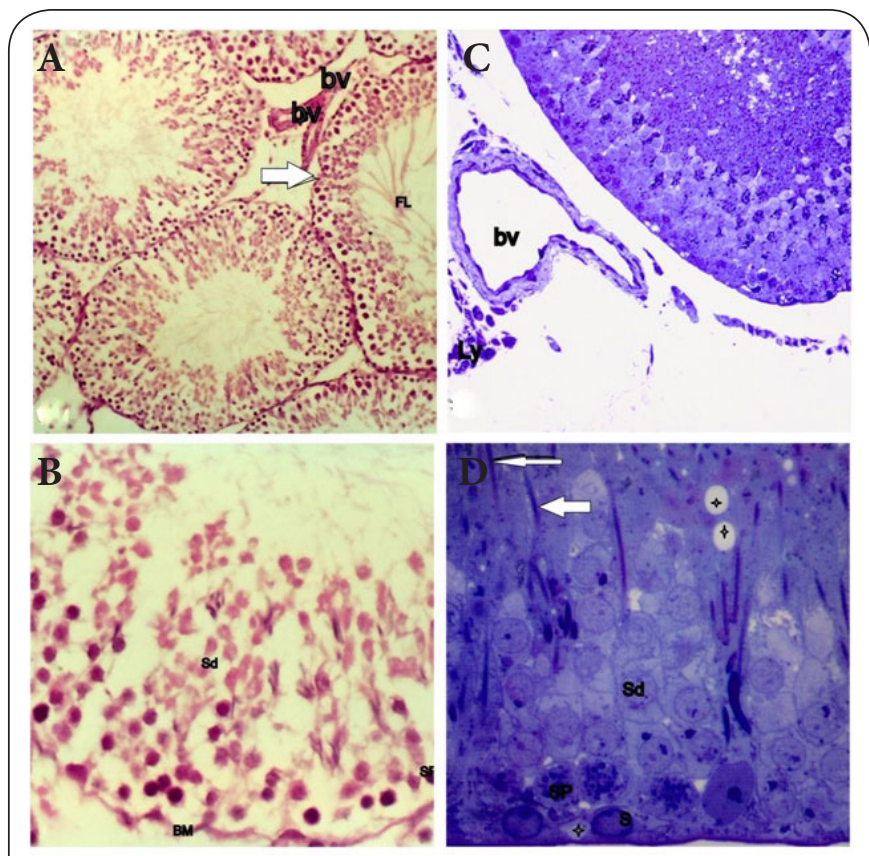

Figure 3. Photomicrograph of sections in treated tests (T2); A. Some seminiferous tubules with irregular outline (arrow). The flagella of mature sperms are seen in the lumen of the tubules (FL). The interstitial spaces in-between the tubules contain Leydig cells (Ly), congested blood vessels (bv) (H\&E $\mathrm{x} 100)$. B. 1ry spermatocyte (Sp), round spermatid (Sd) resting on thin, irregular basement membrane (BM) (H\&E x400). C. Seminefrous tubules with interstial cells of leydig(Ly) and blood vessel (bv) (Touldine blue x100). D. Higher magnification of $\mathbf{C}$, showing Sertoli cells (S), 1ry spermatocyte $(\mathrm{Sp})$, rounded spermatids (Sd), elongated spermatid (arrows) Areas of intercellular vacuoles are detected $\left({ }^{*}\right)$ (Touldine blue $\mathrm{x} 400$ ). 

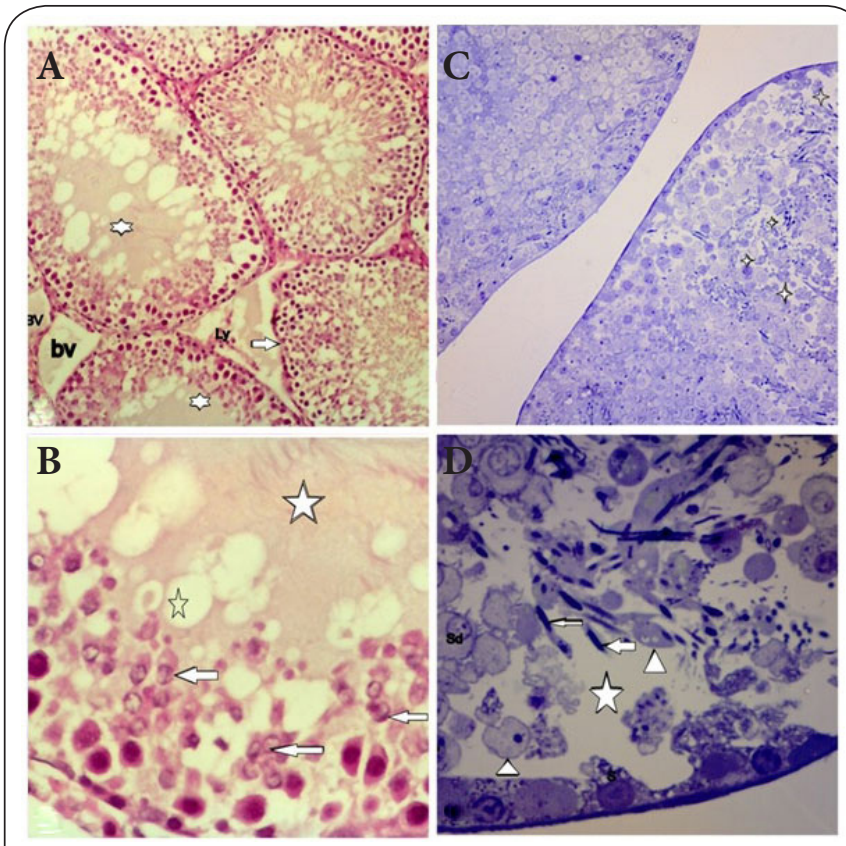

Figure 4. Photomicrograph of sections in treated tests (T3); A. Some seminiferous tubules with irregular outline (arrow), and acidophilic exudate in their lumen and interestial space ${ }^{*}$ ). Interstial cells of leydig (Ly) and congested blood vessel (bv) are noticed (H\&E x100). B. Some spermatogenic cells showed signs of degeneration, vacuolated cytoplasm and pyknotic nuclei (arrows). Incresed areas of cellular loss and vaculation. And acidophilic exudate in the lumen $\left.{ }^{*}\right)(\mathrm{H} \& \mathrm{E}$ $\mathrm{x} 400)$. C. Seminefrous tubules with intercellular vaculation $\left({ }^{*}\right)$ (Touldine blue x100). D. Higher magnification of C, showing Sertoli cells (S), rounded spermatids (Sd), elongated spermatid (arrows) Areas of intercellular vacuoles are detected $\left({ }^{*}\right.$ ).

Degnerated cells with pyknotic nuclei (arrow heads) (Touldine blue $\mathrm{x} 400)$.

with rounded nucleus and dispersed granular chromatin. The cytoplasm showed mitochondria, ribosomes, and lysosmoes (Figure 5B). The rounded spermatids showed rounded nucleus with fine granular chromatin. Acrosomal vesicle was apparent over the anterior part of the nucleus to form acrosomal cap. The cytoplasm contained mitochondria and ribosomes (Figure 5C). The fusiform spermatids showed elongated pyriform nuclei. Acrosomal cap could be noticed on the anterior part of the nucleus (Figures 5D and 5E). The interstitial cells of Leydig showed nuclei with thin peripheral rim of chromatin. The cytoplasm showed organelles like mitochondria, lysosomes and smooth endoplasmic reticulum (Figure 5F).

\section{Group 2 (treated-T1)}

The ultrastructure of the treated testis revealed normal Sertoli cells, which showed triangular nucleus with prominent nucleolus and fine granular chromatin. The cytoplasm contained some normal and some dilated mitochondria (Figure 6A). The spermatogonia appeared large rounded cell, with irregular nuclear membrane, the cytoplasm contained ballooned
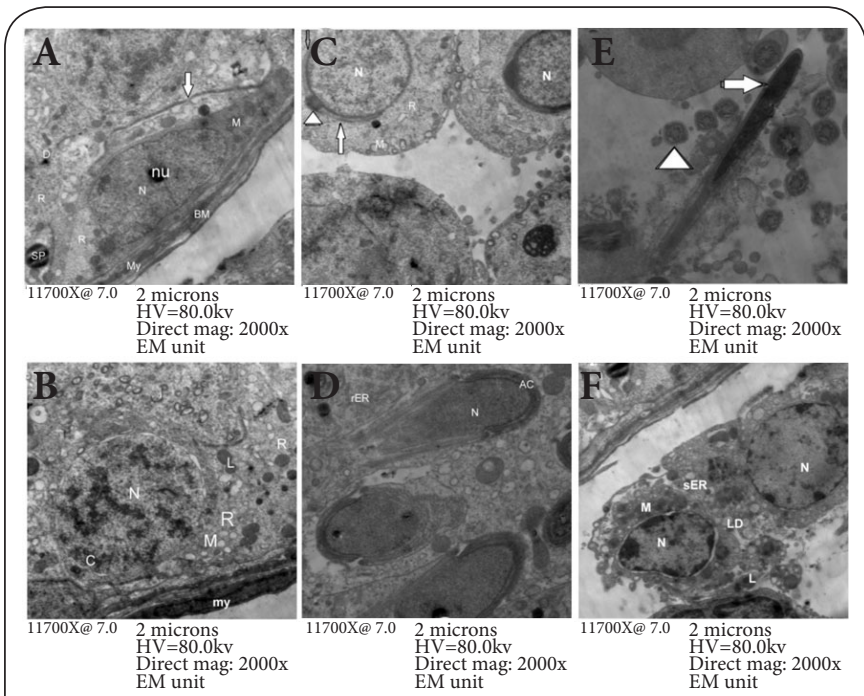

Figure 5. Photomicrogragh of ultrastructure of the control testis A. Sertoli cell, resting on the basement membrane(BM) with adjacent myoid cell (My). The nucleus appears triangular and euchromatic $(\mathrm{N})$ with well developed nucleolus $(\mathrm{nu})$. The cytoplasm shows some organelles, mitochondria (M), and ribosomes (R). The inter-Sertolijunctional specialization with adjacent cells is apparent (arrow). B. The primary spermatocytes appear as large rounded cells, with rounded nucleus $(\mathrm{N})$ and dispersed granular chromatin $(\mathrm{C})$. The cytoplasm shows mitochondria(M), ribosomes(R)lysosmoes (L). C. The rounded spermatids with rounded nucleus with fine granular chromatin $(\mathrm{N})$. Acrosomal vesicle is apparent (arrow head) to form acrosomal cap (arrows). The cytoplasm contains mitochondria (M) and ribosomes(R). D. The fusiform spermatids with elongated pyriform nuclei $(\mathrm{N})$. Acrosomal cap is noticed (Ac). (E) Mature sperm (arrow), multiple cross sections of sperm middle piece (arrow head). (F) The interstitial cells of Leydig, nucleus with thin peripheral rim of chromatin $(\mathrm{N})$. The cytoplasm organelles like mitochondria (M), lysosomes(L), lipid droplet (LD) and smooth endoplasmic reticulum (sER).

mitochondria, lysosmomes, vacuoles, ribosomes and smooth endoplasmic reticulum. 1ry spermatocyte appear with large rounded nucleus (Figures $6 \mathrm{~B}$ and $\mathbf{6 C}$ ). Rounded spermatids appeared with spherical nuclei and incomplete acrosomal caps. Cross sections of the middle pieces of numerous spermatozoa could be also seen (Figure 6D). The elongated spermatids showed pyriform shaped nuclei with acrosomal cap (Figure 6E). The interstitial cells of Leydig appeared with slight indentation in the nuclear membrane. The cytoplasm contained mitochondria, lysosomes and vacuoles (Figure 6F).

\section{Group 3 (treated-T2)}

The examination of the treated testis in this group showed abnormal structure of Sertoli cells, its nucleus appeared with irregular nuclear membrane, the cytoplasm contained ballooned mitochondria. The inter-Sertolijunctional specialization with adjacent cells was interrupted (Figure 7A). The spermatogonia showed nucleus with irregular nuclear 


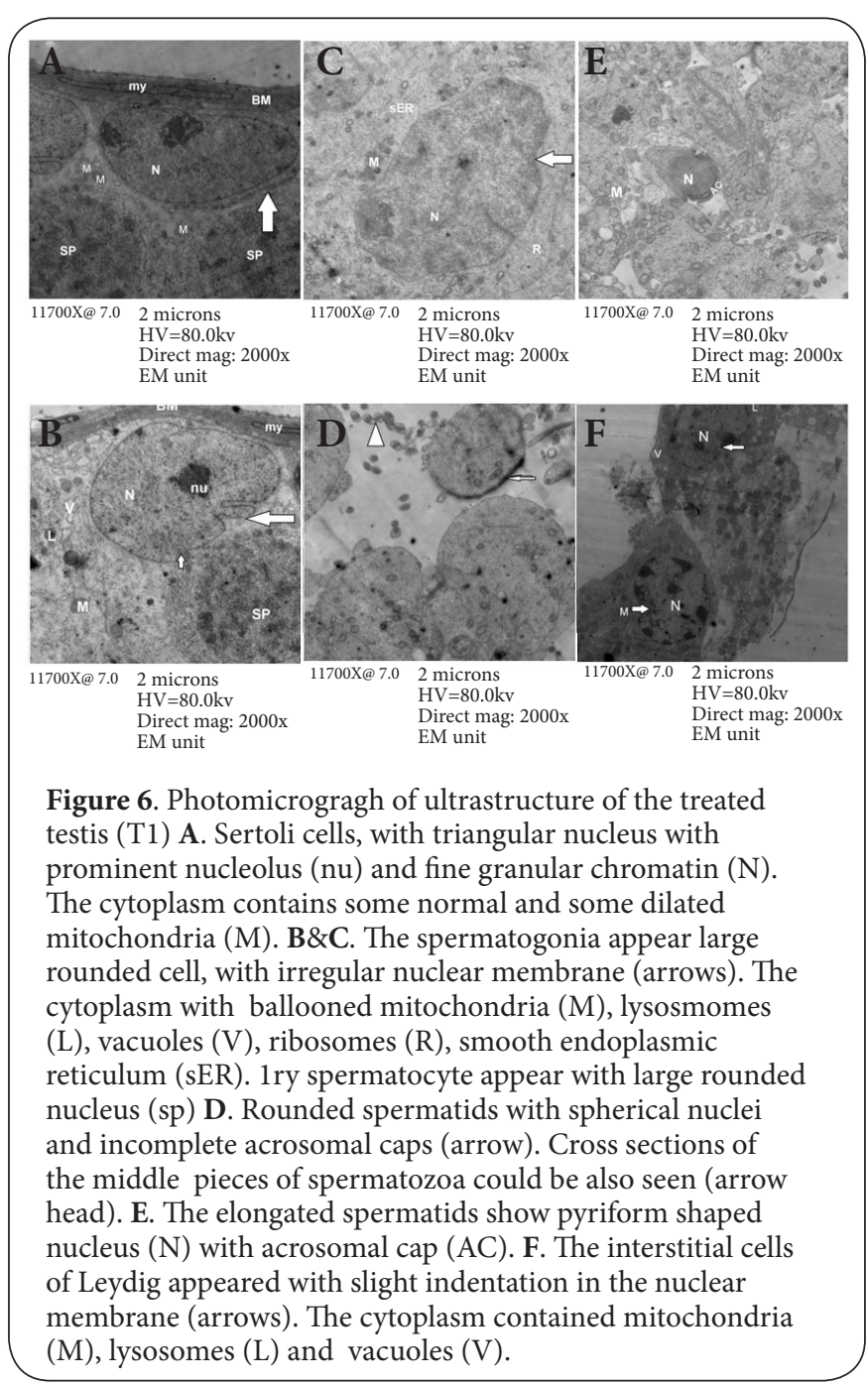

membrane, the cytoplasm contained ballooned mitochondria, ribosomes, dilated smooth cytoplasmic reticulum and some vaculated areas (Figure 7B). Round spermatid showed rounded nucleus with incomplete acrosomal caps. The cytoplasm contained rounded mitochondriaand ribosomes (Figure 7C). The elongated spermatids showed pyriform shaped nuclei. Ectoplasmic specialization could be observed between the Sertoli cell and the spermatids. The ectoplasmic specialization composed of three layers; Sertoli cell plasma membrane, surface cistern of smooth endoplasmic reticulum that lies parallel to the plasma membrane, and layer of actin filaments located between the plasma membrane and surface cistern (Figure 7D). Some abnormal forms of sperms could be seen (Figures 7D and 7E). The interstitial cells of Leydig appeared with indented nuclei. The cytoplasm contained lysosomes, mitochondria, and vacuoles (Figure 7F).

\section{Group 4 (treated-T3)}

The examination of the treated testis in this group showed abnormal structure of Sertoli cells. It showed triangular

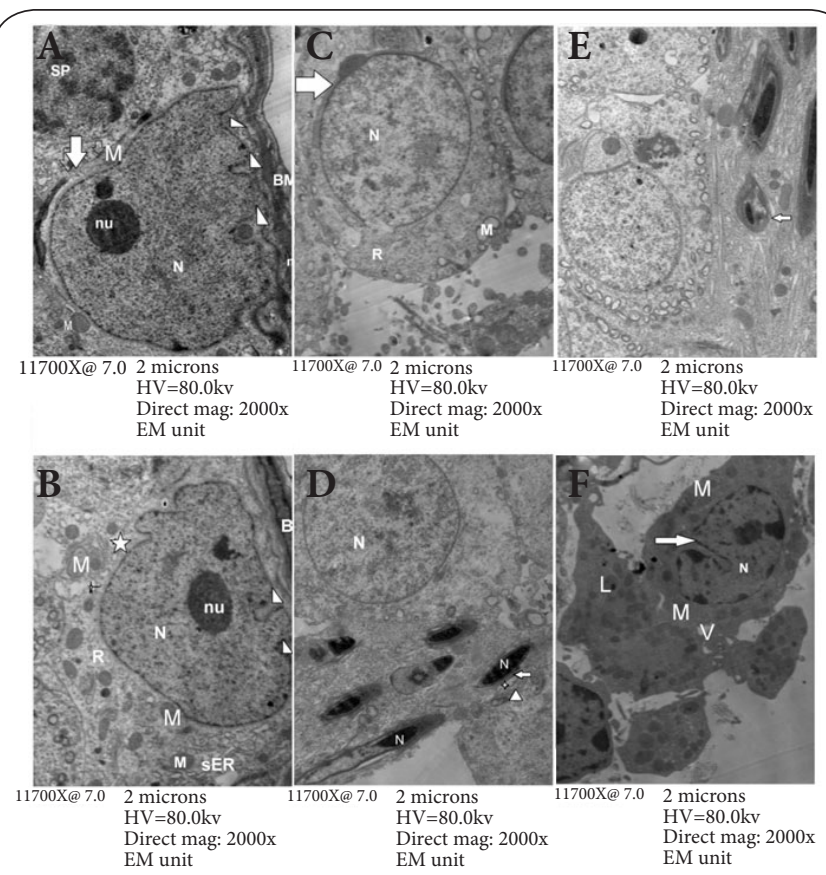

Figure 7. Photomicrogragh of ultrastructure of the treated testis (T2) A. Sertoli cell nucleus with irregular nuclear membrane (arrow heads) and fine granular chromatin. The cytoplasm contains ballooned mitochondria (M). The inter-Sertoli junctional specialization with adjacent cells is interrupted (arrow). B. The spermatogonia showed nucleus with irregular nuclear membrane (arrow heads). The cytoplasm shows ballooned mitochondria (M), ribosomes (R), dilated smooth cytoplasmic reticulum (sER) and some vaculated areas $\left.{ }^{*}\right)$. C. Round spermatid with rounded nucleus and incomplete acrosomal caps (arrow). The cytoplasm contains rounded mitochondria (M) and ribosomes(R). D. The elongated spermatids with pyriform shaped nuclei $(\mathrm{N})$. Ectoplasmic specialization can be observed between the Sertoli cell and the spermatids. It is made of three layers; Sertoli cell plasma membrane (arrow head), surface cistern of smooth endoplasmic reticulum that lies parallel to the plasma membrane $\left.{ }^{*}\right)$, and layer of actin filaments located between the plasma membrane and surface cistern (arrow). E. Some abnormal forms of sperms can be seen (arrow). F. The interstitial cells of Leydig appear with indented nuclei (arrow). The cytoplasm contains lysosomes (L), rounded mitochondria $(\mathrm{M})$, and vacuoles $(\mathrm{V})$.

nucleus with irregular membrane, prominent nucleolus, the cytoplasm contained large cytoplasmic clear vacuole, dilated smooth endoplasmic reticulum and lysosome. The inter-Sertolijunctional specialization with adjacent cells was disturbed (Figure 8A). The adjoining primary spermatocytes cells exhibited large nucleus with irregular membrane and clumped chromatin (Figure 8B). Round spermatid showed indented nucleus with dense clumped chromatin. There was complete loss of acrosomal caps. The cytoplasm showed vacuoles and ballooned mitochondria. Some abnormal forms of elongated spermatids were also noticed (Figure $\mathbf{8 C}$ ). The interstitial cells of Leydig appeared with indented nuclei and 


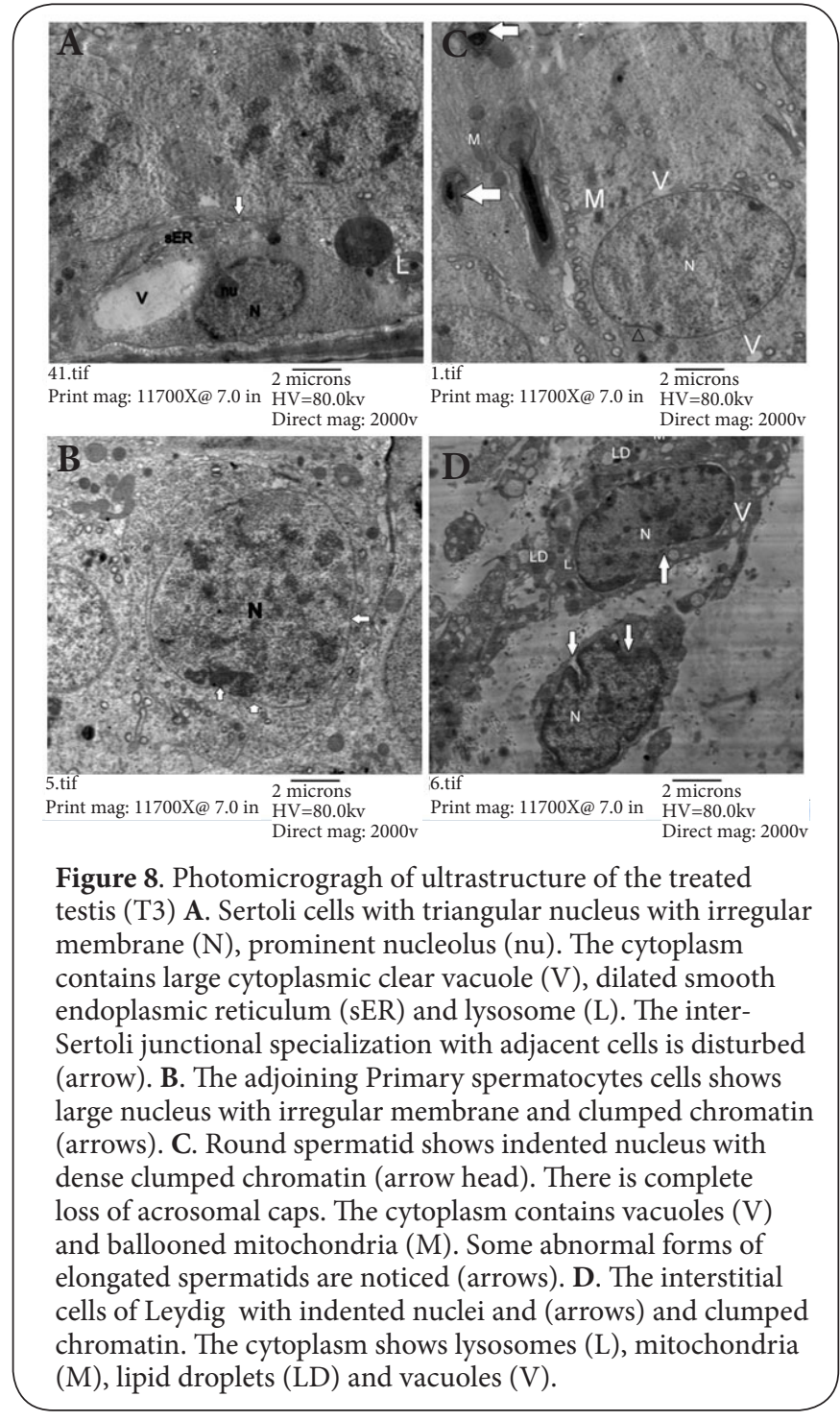

clumped chromatin. The cytoplasm contained lysosomes, mitochondria, lipid droplets and vacuoles (Figure 8D).

\section{Morphometric results and statistical analysis Weight of testis}

There was no significant change in testicular weight between control and treated groups (Graph 1).

\section{The mean diameter of seminefrous tubules}

In comparison with thecontrol group, the mean diameter of seminiferous tubules showed a significant increase in the treated groups (Graph 2).

\section{The number of germ cells}

In comparison with the control group, the mean number of germ cells showed a significant decrease in the treated groups (Graph 3).
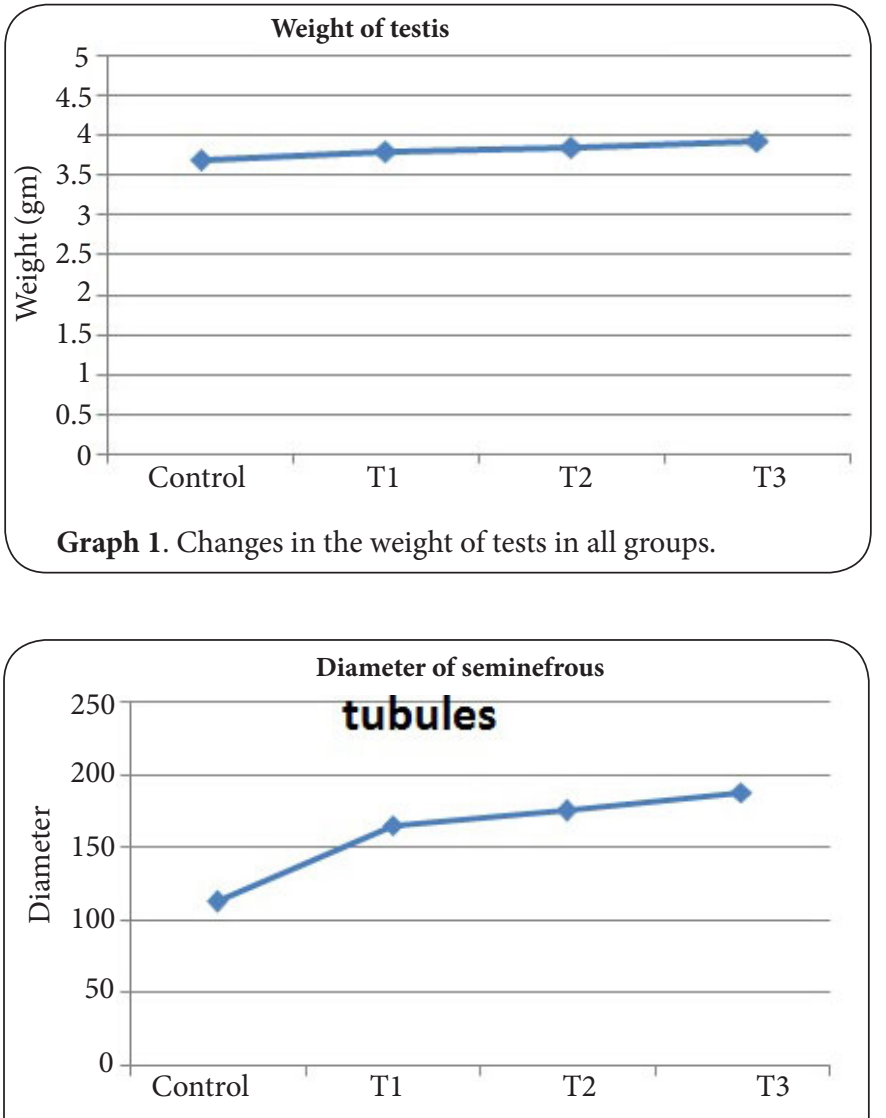

Graph 2. Changes in the diameter in seminefroustubules in all groups.

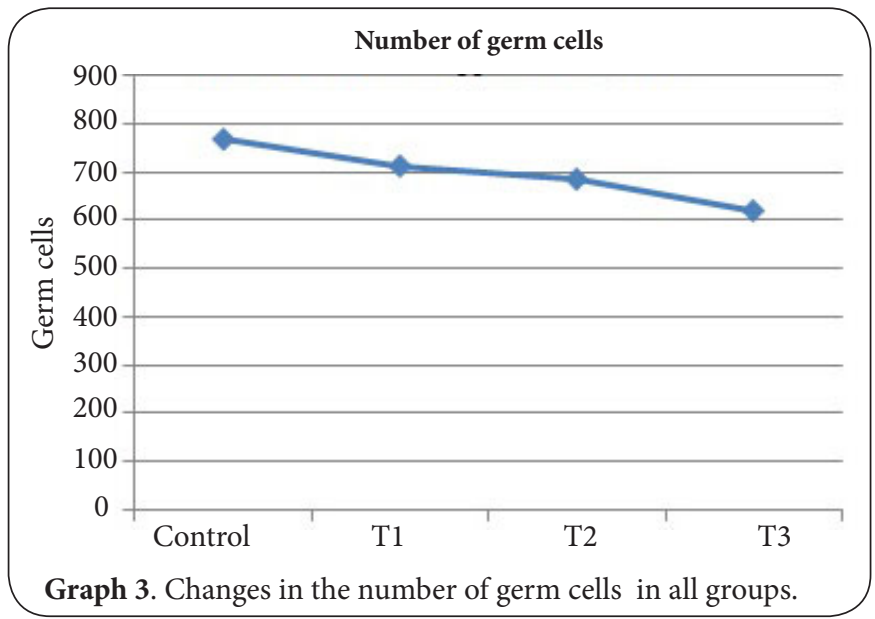

\section{Discussion}

The PDE- 5 inhibitors; sildnafile, tadalafil and vardenafil helped to treat the erectile dysfunction. All three drugs are safe and tolerable. Tadalafil improved erectile dyfunction even in males with type 1 or type 2 diabetes [14].

In this study, the control rat testis showed multiple rounded seminiferous tubules with regular outlines. The lining 
epithelium consisted of Sertoli cells and other germinal cells. Sertoli cells appeared pyramidal in shape and resting on the basement membrane. The germinal epithelium consisted of spermatogonia, 1ry spermatocytes, rounded spermatids and elongated spermatids. The interstitial spaces in-between the tubules contained Leydig cells and some blood vessels. The ultrastructure of the Sertoli cell showed that the nucleus appeared triangular and euchromatic with well developed nucleolus. The inter-Sertoli junctional specialization with adjacent cells was apparent. The primary spermatocytes appeared as large rounded cells, with rounded nucleus and dispersed granular chromatin. The rounded spermatids showed rounded nucleus with fine granular chromatin. Acrosomal vesicle was apparent over the anterior part of the nucleus. The fusiform spermatids showed elongatedpyriform nuclei. Acrosomal cap could be noticed on the anterior part of the nucleus. The interstitial cells of Leydig showed nuclei with thin peripheral rim of chromatin. This comes in agreement with the histological and ultrasructure of the controladult rat testis [15].

The treated group testicular sections which received the least dose of tadalafil, $0.9 \mathrm{mg} / \mathrm{kg}$ orally, showed seminiferous tubules with germinal epithelium. The flagella of sperms were obvious in the lumen. Areas of intercellular vacuoles were detected. The interstitial space showed some Leydig cells separated by congested blood vessels. The ultrastructure of the treated testis revealed normal Sertoli cells, which showed triangular nucleus with prominent nucleolus and fine granular chromatin. The cytoplasm contained some normal and some dilated mitochondria. The spermatogonia appeared as rounded cell, with irregular nuclear memmbrane. Rounded spermatids appeared with spherical nuclei and incomplete acrosomal caps. Cross sections of the middle pieces of numerous spermatozoa could be also seen. The elongated spermatids showed pyriform shaped nuclei with acrosomal cap. The interstitial cells of Leydig appeared with slight indentation in the nuclear membrane. The cytoplasm contained mitochondria, lysosomes and vacuoles. The diameter of seminefrous tubule increased in this group when compared with control group. The number of germ cells showed significant decrease in this group when compared with the control group.

In contrast to this study, It was reported that single dose of sildenafil increased the total sperm count and the percente of motile sperms in semen samples after sildenafil intake compared with semen samples before use of sildenafil. However, long time use of sildenafil treatment is associated with a significant decrease in total sperm count. In another study, vardenafil administration $(10 \mathrm{mg})$ showed a significantly increase in the number of spermatozoa and percentage of morphologically normal spermatozoa [16].

In this research, L/M examination of testicular sections of treated group received $1.8 \mathrm{mg} / \mathrm{kg}$, showed some seminiferous tubules with irregular outline. The basement appeared thin,more areas of intercellular vacuoles were detected. The interstitial space showed some Leydig cells seperated by congested blood vessels. The ultrastructure examination, showed abnormal structure of Sertoli cells, the nucleus with irregular nuclear membrane, the cytoplasm contained ballooned mitochondria. The inter-Sertoli junctional specialization with adjacent cells was interrupted. The spermatogonia showed nucleus with irregular nuclear membrane, the cytoplasm contained ballooned mitochondria, ribosomes, dilated smooth cytoplasmic reticulum and some vaculated areas. Round spermatid showed rounded nucleus with incomplete acrosomal caps. The elongated spermatids showed pyriform shaped nuclei. The interstitial cells of Leydig appeared with indented nuclei, the cytoplasm contained lysosomes, mitochondria, and vacuoles. The diameter of seminefrous tubule increased in this group when compared with control group. The number of germ cells showed significant decrease in this group when compared with the control group.

In agreement with this result, it was concluded that tadalafil caused a significant decrease in sperm count and motility with increased incidence of abnormal forms. Histological examination showed loosely packed stroma around seminiferous tubules with reduction in number of spermatogenic cells [12]. Also, it was documented that administration of $50 \mathrm{mg}$ sildenafil caused degeneration of somniferous tubules and the spermatogenic cells. The interstitial tissue showed congested blood vessels, degenerated leydig cells. The basement membrane was thin [17]. It was concluded that of sildenafil citrate $(50 \mathrm{mg})$ administration caused significant reduction in the number of sperms [18].

In contrast, it was reported that administration of 10-mg and 20-mg tadalafil in human every day for six months, showed insignificant change in the sperm morphology [19]. Also, it was found that administration of single dose of sildenafil (50 $\mathrm{mg}$ ) in young infertile males resulted in significant increase in sperm motility, while, tadalafil single dose $(20 \mathrm{mg})$ caused reduction in the motility of the sperms. It was found that impact of sildenafil on the motility of sperms mightbe due tochanges in mitochondria and calcium channels [20].

The Sertoli cell tight junctions is a vital component of the blood-testis barrier which is essential for normal spermatogenesis. The interrupted inter-Sertoli junctional specialization in case of tadalafil administration may be explained by the fact defective testicular blood barrier could cause opening of the testicular blood barrier gate. This disturb the protective and nutritional function of the barrier and impair spermatogenesis [21]. $\mathrm{L} / \mathrm{M}$ examination of testicular sections of the group received $2.6 \mathrm{mg} / \mathrm{kg}$ showed seminiferous tubules with irregular outline with acidophilic exudate in their lumen and congested blood vessels in between. Some spermatogenic cells showed signs of degeneration; vacuolated cytoplasm and pyknotic nuclei. Increased areas of cellular loss and vaculation in the tubules. The ultrastructure of treated testis in this group showed abnormal structure of Sertoli cells. It showed triangular nuclei with irregular membrane, the cytoplasm contained large 
cytoplasmic clear vacuoles, dilated smooth endoplasmic reticulum and lysosome. The inter-Sertoli functional specialization with adjacent cells was disturbed. Round spermatid showed indented nucleus with dense clumped chromatin. There was complete loss of acrosomal cap. The cytoplasm showed vacuoles and ballooned mitochondria. Some abnormal forms of elongated spermatids were also noticed with defected ectoplamic specialization. The interstitial cells of Leydig appeared with indented nuclei, the cytoplasm contained lysosomes, mitochondria, lipid droplets and vacuoles. The diameter of seminefrous tubule increased in this group when compared with control group. The number of germ cells showed significant decrease in this group when compared with the control group.

In agreement with this result, it was documented that administration of $100 \mathrm{mg}$ sildenafil caused degeneration of somniferous tubules with thin basement membrane and thespermatogenic cells, the interstitial tissue showed congested blood vessels, degenerated leydig cells [17]. However, it was noticed that $100-\mathrm{mg}$ sildenafil citrate in diabetic patients increased sperm motility and semen volume [22].

In the same time, it was documented that administration of 100-mg singledose of sildenafil had no significant effect on sperm motility,sperm count or morphology in human [23]. Also, single dose of vardenafil ( $20 \mathrm{mg}$ ) had no significant effects on sperm motility, sperm viability, and sperm morphology in males [24].

In this study, round spermatid in treated rats showed incomplete or absent acrosomal cap. Some elongated spermatids showed abnormal nuclei, shape and defective ectoplasmic specialization. According to some authors, the ectoplasmic specialization, which is unique to the testis, have an essential role in spermatid nuclear shaping. F-actin filaments from normal Sertoli cells enhance spermatid head elongation [25]. So, abnormal Sertoli cell may affect spermatid nuclear shaping.

On the other hand, it was reported that PDE5 inhibitors may enhance the capacitation of spermatids $[18,26,27]$. cGMPcan opencyclic nucleotide-gated channels for calcium entry inside he spermatozoa to initiate the acrosomalreaction. However, PDE5 cause hydrolysis ofcGMP, so, inhibition of PDE5 by sildenafil citrate can trigger the effect of cGMP on sperm acrosomal reaction [28].

In this investigation, the diameter of seminefrous tubules increased in treated rats when compared with control rats. Similar result was reported in case of sildenafil and explained by the vasoactive of the drug, which may occur in other PDE5 inhibitors [29].

\section{Conclusion}

It can be concluded that, long-term daily use of tadalafil can lead to noticeable pathological effect in the testis which may be implicated in male fertility and this effect is dose dependent, so the effect of tadalafil necessitates further investigations.
Competing interests

The author declares that he has no competing interests.

Acknowledgement

The author thanks Prof. Dr. Amany M Shams professor of Anatomy and all the staff members of Anatomy and Embryology Department in Faculty of Medicine, Mansoura University, Egypt, for their cooperation and helpful comments during this work.

\section{Publication history}

Editor: Lingyan Wang, Oregon Health \& Science University, Portland. EIC: Gaetano Giuseppe Magro, University of Catania, Italia. Received: 30-Jun-2015 Final Revised: 01-Aug-2015 Accepted: 21-Aug-2015 Published: 27-Aug-2015

\section{References}

1. Dimitriadis F, Tsampalas S, Tsounapi P, Giannakis D, Chaliasos N, Baltogiannis D, Miyagawa I, Saito M, Takenaka A and Sofikitis N. Effects of phosphodiesterase- 5 inhibitor vardenafil on testicular androgenbinding protein secretion, the maintenance of foci of advanced spermatogenesis and the sperm fertilising capacity in azoospermic men. Andrologia. 2012; 44 Suppl 1:144-53. | Article I PubMed

2. Boolell M, Allen MJ, Ballard SA, Gepi-Attee S, Muirhead GJ, Naylor AM, Osterloh IH and Gingell C. Sildenafil: an orally active type 5 cyclic GMPspecific phosphodiesterase inhibitor for the treatment of penile erectile dysfunction. Int J Impot Res. 1996; 8:47-52. | Article | PubMed

3. Rosen RC and Kostis JB. Overview of phosphodiesterase $\mathbf{5}$ inhibition in erectile dysfunction. Am J Cardiol. 2003; 92:9M-18M. | $\underline{\text { Article | PubMed }}$

4. Lue TF. Erectile dysfunction. N Engl J Med. 2000; 342:1802-1813.

5. Galie N, Ghofrani HA, Torbicki A, Barst RJ, Rubin LJ, Badesch D, Fleming T, Parpia T, Burgess G, Branzi A, Grimminger F, Kurzyna M and Simonneau G. Sildenafil citrate therapy for pulmonary arterial hypertension. $N$ Engl J Med. 2005; 353:2148-57. | Article | PubMed

6. Burls A, Gold L and Clark W. Systematic review of randomised controlled trials of sildenafil (Viagra) in the treatment of male erectile dysfunction. Br J Gen Pract. 2001; 51:1004-12. | Article | PubMed Abstract | PubMed Full Text

7. Padma-Nathan $\mathrm{H}$ and Giuliano F. Oral drug therapy for erectile dysfunction. Urol Clin North Am. 2001; 28:321-34. | Article I PubMed

8. Porst H, Rosen R, Padma-Nathan H, Goldstein I, Giuliano F, Ulbrich E and Bandel T. The efficacy and tolerability of vardenafil, a new, oral, selective phosphodiesterase type 5 inhibitor, in patients with erectile dysfunction: the first at-home clinical trial. Int J Impot Res. 2001; 13:192-9. | Article | PubMed

9. Gresser $\mathrm{U}$ and Gleiter $\mathrm{CH}$. Erectile dysfunction: comparison of efficacy and side effects of the PDE-5 inhibitors sildenafil, vardenafil and tadalafil--review of the literature. Eur J Med Res. 2002; 7:435-46. | Pdf | PubMed

10. Kulkarni SK and Patil CS. Phosphodiesterase 5 enzyme and its inhibitors: update on pharmacological and therapeutical aspects. Methods Find Exp Clin Pharmacol. 2004; 26:789-99. I Article I PubMed

11. Arlond LM. Vardenafil and tadalafil Options for erectile dysfunction, Two new PDE-5 inhibitors have demonstrated efficacy and tolerability in clinical trials. Current Pyscatry. 2004; 3:51-52.

12. Khalaf MA, Abbas MF and El-Fakahany HM. Effects of chronic tadalafil use on the testes and sperm parameters of old albino rats. Andrologia. 2012; 44 Suppl 1:370-5. | Article | PubMed

13. Hayat M. Principles and techniques of electron microscopy, biological applications. $3^{\text {rd }}$ ed. CRC press. $1989 ; 24-74$.

14. Saenz de Tejada I, Anglin G, Knight JR and Emmick JT. Effects of tadalafil on erectile dysfunction in men with diabetes. Diabetes Care. 2002; 25:2159-64. | Article | PubMed

15. Halawa AM. Effect of Sildenafil Adminstration on Ischemia/Reperfusion of the Testis in Adult Albino Rat Light and Electron Microscopic Study. Egypt. J. Histol. 2010; 33:380-395. I Pdf 
16. Dimitriadis F, Giannakis D, Pardalidis N, Zikopoulos K, Paraskevaidis E, Giotitsas N, Kalaboki V, Tsounapi P, Baltogiannis D, Georgiou I, Saito M, Watanabe T, Miyagawa I and Sofikitis N. Effects of phosphodiesterase-5 inhibitors on sperm parameters and fertilizing capacity. Asian J Androl. 2008; 10:115-33. | Article | PubMed

17. Al-Fartosi KG. Effect of Long Term Adminstration of Sildenafil Citrate (Viagra) on Some Sperm Characteristic and Tests Architecture of Male Rats. Bas. J. Vet. Res. 2009; 8:91-103. | Pdf

18. Glenn DR, McVicar CM, McClure N and Lewis SE. Sildenafil citrate improves sperm motility but causes a premature acrosome reaction in vitro. Fertil Steril. 2007; 87:1064-70. | Article | PubMed

19. Hellstrom WJ, Gittelman M, Jarow J, Steidle C, McMurray J, Talley $D$, Watts $S$, Mitchell $C L$ and McGill JM. An evaluation of semen characteristics in men 45 years of age or older after daily dosing with tadalafil 20mg: results of a multicenter, randomized, double-blind, placebo-controlled, 9-month study. Eur Urol. 2008; 53:1058-65. | Article I PubMed

20. Pomara G, Morelli G, Canale D, Turchi P, Caglieresi C, Moschini C, Liguori G, Selli C, Macchia E, Martino E and Francesca F. Alterations in sperm motility after acute oral administration of sildenafil or tadalafil in young, infertile men. Fertil Steril. 2007; 88:860-5. | Article | PubMed

21. McCabe MJ, Tarulli GA, Meachem SJ, Robertson DM, Smooker PM and Stanton PG. Gonadotropins regulate rat testicular tight junctions in vivo. Endocrinology. 2010; 151:2911-22. | Article | PubMed Abstract | PubMed Full Text

22. Ali ST and Rakkah NI. Neurophysiological role of sildenafil citrate (Viagra) on seminal parameters in diabetic males with and without neuropathy. Pak J Pharm Sci. 2007; 20:36-42. | Article | PubMed

23. Purvis K, Muirhead GJ and Harness JA. The effects of sildenafil on human sperm function in healthy volunteers. Br J Clin Pharmacol. 2002; 53 Suppl 1:53S-60S. | Article | PubMed Abstract | PubMed Full Text

24. Bauer R. J and Rohde G. A single oral dose of vardenafil had no acute effect on sperm motility in healthy males. 27th Annual Meeting of the American Society of Andrology. April 24-27, 2002. Seattle, Washington, USA. J Androl. 2002; 26.

25. Kierszenbaum AL and Tres LL. The acrosome-acroplaxome-manchette complex and the shaping of the spermatid head. Arch Histol Cytol. 2004; 67:271-84. | Article | PubMed

26. Lefievre L, De Lamirande E and Gagnon C. The cyclic GMP-specific phosphodiesterase inhibitor, sildenafil, stimulates human sperm motility and capacitation but not acrosome reaction. J Androl. 2000; 21:929-37. | Article | PubMed

27. Cuadra DL, Chan PJ, Patton WC, Stewart SC and King A. Type 5 phosphodiesterase regulation of human sperm motility. Am J Obstet Gynecol. 2000; 182:1013-5. | Article | PubMed

28. Biel M, Sautter A, Ludwig A, Hofmann F and Zong X. Cyclic nucleotidegated channels--mediators of NO:cGMP-regulated processes. Naunyn Schmiedebergs Arch Pharmacol. 1998; 358:140-4. | Article | PubMed

29. Erol B, Tokgoz H, Hanci V, Bektas S, Akduman B, Yencilek F, Mungan G and Mungan $A$. Vardenafil reduces testicular damage following ischemia/ reperfusion injury in rats. Kaohsiung J Med Sci. 2009; 25:374-80. I Article I PubMed

\section{Citation:}

Hashish HA. Evaluation of histopathological and ultrastructural changes in the testis of tadalafil treated adult male albino rats.

J Histol Histopathol. 2015; 2:18.

http://dx.doi.org/10.7243/2055-091X-2-18 